\title{
Induction therapy with bortezomib and dexamethasone followed by autologous stem cell transplantation versus autologous stem cell transplantation alone in the treatment of renal $\mathrm{AL}$ amyloidosis: a randomized controlled trial
}

Xianghua Huang, Qingwen Wang, Wencui Chen, Caihong Zeng, Zhaohong Chen, Dehua Gong, Haitao Zhang and Zhihong Liu*

\begin{abstract}
Background: Although the use of bortezomib alone and in combination with steroids has shown efficacy in AL amyloidosis, its role in combination with high-dose melphalan and autologous stem cell transplantation (HDM/SCT) is unknown. In this study, we evaluated bortezomib in combination with dexamethasone (BD) for induction chemotherapy prior to HDM/SCT.

Methods: This was a single-center, prospective, randomized controlled trial comparing induction therapy consisting of two BD cycles followed by HDM/SCT (BD + HDM/SCT) with HDM/SCT alone in the treatment of patients with newly diagnosed $\mathrm{AL}$ amyloidosis. The hematological and organ responses of the patients were assessed every three months post HDM/SCT.
\end{abstract}

Results: Fifty-six patients newly diagnosed with renal (100\%), cardiac (57.1\%), liver (7.1\%), or nervous system (8.9\%) AL amyloidosis were enrolled in this study; 28 patients were assigned to each arm. Two patients died within 100 days of HDM/SCT (3.6\% treatment-related mortality). The overall hematologic response rates in the BD + HDM/ SCT arm and HDM/SCT arm at three, six and twelve months were $78.5 \%$ versus $50 \%, 82.1 \%$ versus $53.5 \%$ and $85.7 \%$ versus 53.5\%, respectively. In the BD + HDM/SCT arm, 15 (53.5\%) patients achieved a hematologic response after $\mathrm{BD}$ and before HDM/SCT. An intention-to-treat analysis revealed a higher rate of complete remission in the BD + HDM/ SCT arm at both 12 and 24 months (67.9\% and 70\%, respectively) than with the HDM/SCT-only therapy (35.7\% and $35 \%$, respectively, $P=0.03$ ). After a median follow-up of 28 months, the survival rates at 24 months post-treatment start were $95.0 \%$ in the BD + HDM/SCT group and $69.4 \%$ in the HDM/SCT alone group $(P=0.03)$.

Conclusions: Our preliminary data suggest that the outcome of treating AL amyloidosis with BD induction and HDM/SCT was superior to the outcome of the HDM/SCT treatment alone.

Trial registration: This trial has been registered at clinicaltrials.gov with the number NCT01998503.

Keywords: AL amyloidosis, Bortezomib, Autologous stem cell transplantation

\footnotetext{
* Correspondence: liuzhihong@nju.edu.cn

Research Institute of Nephrology, Jinling Hospital, Nanjing University School of Medicine, Nanjing 210002, China
}

\section{Biomed Central}

(C) 2014 Huang et al.; licensee BioMed Central Ltd. This is an Open Access article distributed under the terms of the Creative Commons Attribution License (http://creativecommons.org/licenses/by/2.0), which permits unrestricted use, distribution, and reproduction in any medium, provided the original work is properly cited. The Creative Commons Public Domain Dedication waiver (http://creativecommons.org/publicdomain/zero/1.0/) applies to the data made available in this article, unless otherwise stated. 


\section{Background}

$\mathrm{AL}$ amyloidosis is the most common form of systemic amyloidosis, and it arises from the production of monoclonal free light chains (FLCs) by a pathological plasma cell clone [1]. The deposition of insoluble amyloid fibrils in vital organs, such as the heart, kidney, liver, and nerves, can lead to progressive organ dysfunction and death [2]. AL amyloidosis is often devastating, and the median survival rate of untreated patients with this lethal disease is only 10 to 14 months from diagnosis [3]. The treatment for $\mathrm{AL}$ amyloidosis is aimed at reducing FLCs by eradicating the plasma cells [4] that produce them, although the options currently available for this treatment are limited [5].

$\mathrm{AL}$ amyloidosis treatments are based on existing multiple myeloma therapies. Melphalan (MEL) and prednisone administration was the first effective regimen developed for $\mathrm{AL}$ amyloidosis; however, the treatment responses are typically slow and rarely result in complete remission [6,7]. An Italian study combining MEL with high-dose dexamethasone (MDex) noted an impressive hematologic response rate of $67 \%$ [8] and long-term remissions in AL amyloidosis [9], and MDex is still considered a standard for non-study, non-transplant intervention because of its low toxicity profile [10]. Alternatively, intensive therapy with highdose MEL and autologous stem cell transplantation (HDM/SCT) is effective in AL amyloidosis and can offer durable remission in some patients $[11,12]$. However, only $25 \%$ of affected patients are eligible for this approach $[13,14]$, and the treatment-related mortality (TRM) with HDM/SCT is high $[11,15,16]$. Accordingly, it is necessary to identify modifications to the HDM/SCT procedure that could improve outcomes in patients with AL amyloidosis.

Novel drugs, including thalidomide [17,18], lenalidomide [19] and bortezomib [20] (alone or in combination with dexamethasone), have recently proven to be effective in the non-transplantation setting. Bortezomib is a reversible proteasome inhibitor that has shown significant activity in patients with multiple myeloma $[21,22]$. Indeed, several studies have confirmed that bortezomib combined with dexamethasone (BD) is an active and fast-acting regimen for AL amyloidosis, even in pretreated patients [20,23-25]. However, the data regarding the toxicity and efficacy of $\mathrm{BD}$ chemotherapy prior to HDM/SCT are limited for patients with AL amyloidosis. Thus, to determine whether induction therapy with BD is advantageous in patients with $\mathrm{AL}$ amyloidosis, we prospectively evaluated a therapeutic regimen consisting of two cycles of $\mathrm{BD}$ chemotherapy followed by HDM/SCT in a single-center study.

\section{Methods}

\section{Patient eligibility}

Patients with newly diagnosed AL amyloidosis were enrolled in this trial, which was approved by the institutional ethical review board of Jinling Hospital. The participants or their guardians provided written informed consent. All patients had amyloid disease, which was confirmed by renal biopsy and documented plasma cell dyscrasia; the AL amyloidosis diagnosis and the assessment of organ involvement were based on consensus criteria [26]. Patients who met the three criteria for multiple myeloma (MM) diagnosis, that is, clonal bone marrow plasma cells $\geq 10 \%$, the presence of serum and/or urinary monoclonal protein and evidence of end-organ damage that can be attributed to the underlying plasma cell proliferative disorder, were excluded [27]. The following HDM/SCT inclusion criteria were applied: age between 18 and 65 years, performance status of 0 to 2 according to Eastern Cooperative Oncology Group (ECOG) criteria [28], a left ventricular ejection fraction (LVEF) $>45 \%$, a serum bilirubin level $\leq 2.0 \mathrm{mg} / \mathrm{dl}$, a pulmonary diffusion capacity $\geq 50 \%$ and a serum creatinine level $\leq 2 \mathrm{mg} / \mathrm{dl}$. Patients were excluded if they had uncompensated congestive heart failure, symptomatic cardiac arrhythmia, or cardiac syncope.

\section{Study design}

In this prospective, randomized controlled study, newly diagnosed AL amyloidosis patients who met the criteria for HDM/SCT were randomized to receive two cycles of BD as induction therapy followed by HDM/ $\mathrm{SCT}(\mathrm{BD}+\mathrm{HDM} / \mathrm{SCT})$ or to receive HDM/SCT alone as an initial treatment. The BD regimen included bortezomib $1.3 \mathrm{mg} / \mathrm{m}^{2}$ i.v. and dexamethasone $40 \mathrm{mg}$ p.o. on days 1 , 4,8 and 11 of the 21 day cycle. This process was repeated for two cycles, after which the patients underwent HDM/ SCT treatment within eight weeks. The stem cells were mobilized with granulocyte colony-stimulating factor alone, and a minimum collection of $2 \times 10^{6} \mathrm{CD} 34^{+} / \mathrm{kg}$ body weight was required. The patients were assigned to one of two MEL dose levels $\left(200 \mathrm{mg} / \mathrm{m}^{2}\right.$ or $\left.140 \mathrm{mg} / \mathrm{m}^{2}\right)$ based on age, cardiac involvement and renal function [29] (Figure 1). Supportive therapy for side effect management was administered according to the clinical requirements. Omeprazole was given as prophylaxis to all patients who received BD induction, but they were not treated with anti-virus prophylaxis. The patients were assessed every three months following HDM/SCT until progression or death. Adverse events (AEs) were recorded throughout the study and were graded according to the National Cancer Institute Common Terminology Criteria for Adverse Events, version 3.0.

\section{Hematologic and organ response criteria}

Hematologic and organ responses were evaluated according to the novel criteria of the International Society of Amyloidosis [30,31] . Hematologic complete response (CR) was defined as normalization of the FLC levels and ratio, negative serum and urine immunofixation. A hematologic very good partial response (VGPR) was 


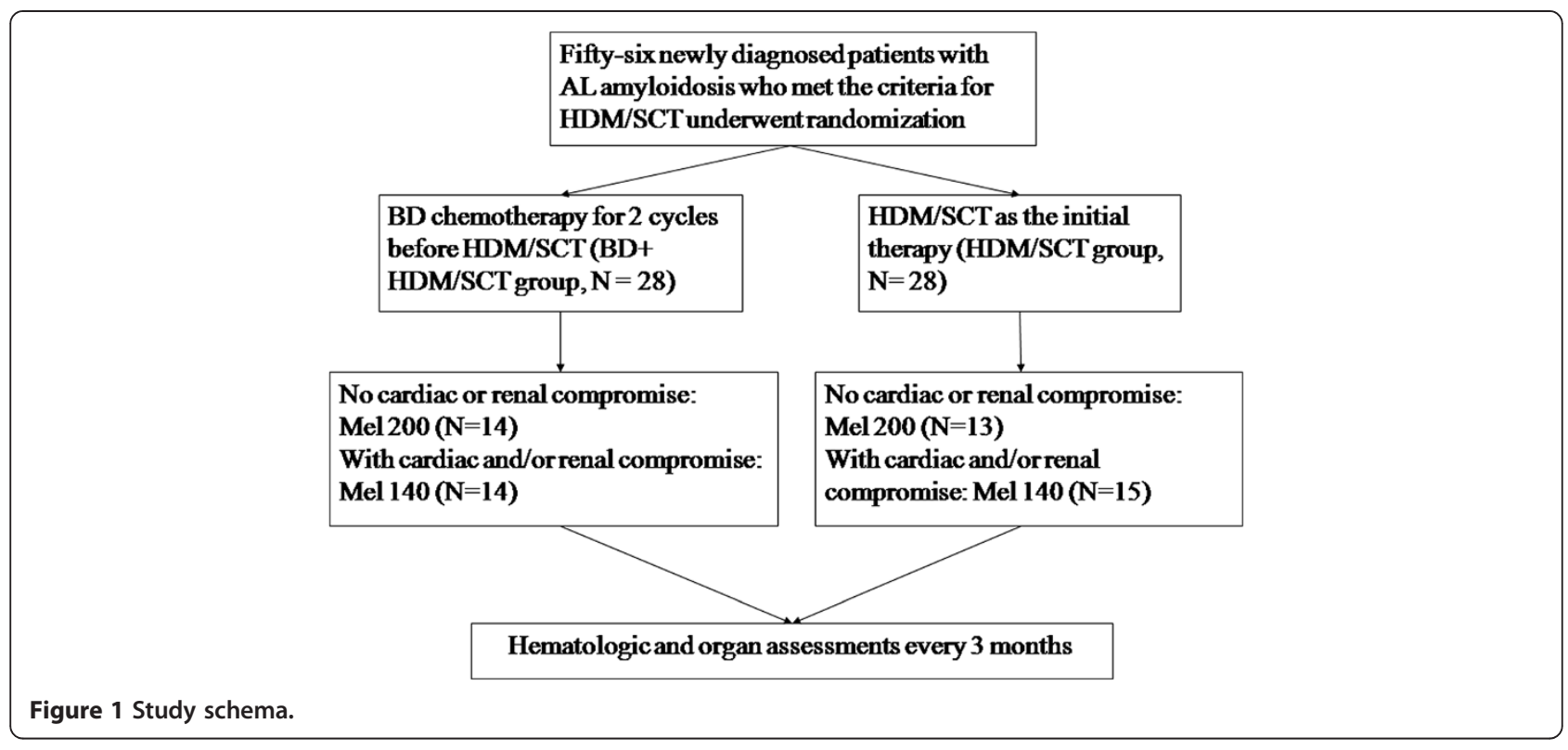

defined as a reduction in dFLCs (difference between involved FLCs and uninvolved FLCs) to $<40 \mathrm{mg} / \mathrm{L}$. A hematologic partial response (PR) was defined as a greater than $50 \%$ reduction in dFLCs. No response (NR) was defined as less than PR. A hematologic progression has three situations: from $C R$, any detectable monoclonal protein or abnormal FLC ratio (the light chain must double); from PR, a $50 \%$ increase in serum $\mathrm{M}$ protein to $>0.5 \mathrm{~g} / \mathrm{dl}$ or $50 \%$ increase in urine $\mathrm{M}$ protein to $>200 \mathrm{mg} /$ day (a visible peak must be present); and an FLC increase of $50 \%$ to $>100 \mathrm{mg} / \mathrm{l}$. The hematological and organ responses were assessed every three months following HDM/SCT.

\section{Statistical analysis}

The protocol was designed as a superiority trial to demonstrate that BD induction followed by HDM/SCT is superior to $\mathrm{HDM} / \mathrm{SCT}$ alone for treating AL amyloidosis. The working hypothesis was that the $\mathrm{BD}$ induction, followed by the HDM/SCT, would improve the hematologic CR rate (estimated to be $30 \%$ in the group assigned to receive the HDM/SCT alone) by $40 \%$ at 12 months. The sample size necessary to detect a significant difference ( $\alpha=0.05,2$-sided) was calculated to be 23 on the basis of 0.8 power. To compensate for the non-assessable patients, we planned to enroll a minimum of 28 patients per group.

The primary end point for this study was a hematologic CR rate 12 months after HDM/SCT. The secondary end points included the organ response rate, overall survival (OS), and progression free survival (PFS) for all patients. OS was defined as the time from the randomization to the date of death from any cause. The survival time was censored at the date of the last contact for the patients who were still alive or lost to follow-up. PFS was defined as the time from the randomization until date of progression, death, or last follow-up. The PFS and OS between the groups were compared using the Kaplan-Meier method. The start date was the date of randomization, and the cutoff date was June 30, 2013.

The t-test for independent samples or the MannWhitney $U$ test was used to compare the continuous data between the groups. The differences between the categorical variables were assessed using Fisher's exact test. Cox proportional hazards were used to calculate the hazard ratios (HRs) for each variable. The $P$ value reported was 2 -sided, and $P<0.05$ was considered to be statistically significant. All analyses were performed using SPSS software (version 13.0, SPSS Inc., Chicago, IL, USA).

\section{Results}

\section{Patient characteristics}

Between June 2009 and June 2012, 56 patients (Table 1) with newly diagnosed, treatment-naive AL amyloidosis who provided informed consent were enrolled and treated in this clinical trial. A total of 28 patients were treated with BD induction followed by HDM/SCT (BD + HDM/SCT), while another 28 patients received only HDM/SCT. The median ages and gender compositions of the patients in the two groups were similar. The median time from diagnosis to transplantation was four months (range, 2 to 16 months) in the $\mathrm{BD}+\mathrm{HDM} / \mathrm{SCT}$ group and two months (range, 1 to 18 months) in the HDM/SCT group $(P=0.07)$. The frequencies of systemic involvement were similar in both groups, and all patients presented with renal involvement, as confirmed by renal biopsy. A total of 17 patients $(60.7 \%)$ in the BD + HDM/SCT group and 16 patients (57.1\%) in the HDM/SCT group had involvement of more 


\section{Table 1 Patient characteristics}

\section{Characteristic}

Age (years)

Median

53

38-65

Range

Male/female (number)

$18 / 10$

Organ involvement, number (\%)

$$
\begin{aligned}
& \text { Kidney } \\
& \text { Heart } \\
& \text { Liver } \\
& \text { Nervous system } \\
& >1 \text { organ involved } \\
& \text { Cardiac stage, number }(\%)^{a} \\
& \text { । } \\
& \text { II } \\
& \text { III }
\end{aligned}
$$

Involved FLC, number (\%)

$$
\text { K }
$$$$
\lambda
$$

Abnormal FLC k-to- $\lambda$ ratio number (\%)

ECOG PS (0/1/2), number (\%)

$$
0
$$$$
1
$$$$
2
$$

24-hour urine protein (g/24 hour)

Albumin (g/L)

Creatinine $(\mathrm{mg} / \mathrm{dL})$

GFR (mL/min)

Marrow plasma cells (\%)

Echocardiogram septal thickness ( $\mathrm{mm}$ )

Ejection fraction (\%)

Alkaline phosphatasea (U/L)

$$
\text { Median }
$$

Range

NT-proBNP (ng/L)

$$
\text { Median }
$$

Range

$>8500 \mathrm{ng} / \mathrm{L}(\%)$

BNP (ng/L)

Median

Range

Troponin-l (ng/ml)

Median

Range

iFLC (mg/L)

$28(100)$

1 (3.6)
$\mathrm{BD}+\mathrm{HDM} / \mathrm{SCT}$ (number $=28$ )

HDM/SCT (number $=28$ )

$P$ value

51.5

0.23

37-63

16/12

0.78

28 (100)

1.0

15 (53.5)

0.79

3 (10.7)

0.61

3 (10.7)

17 (60.7)

$2(7.1)$

1.0

$16(57.1)$

1.0

14 (50)

12 (42.9)

0.86

10 (35.7)

4 (14.3)

11 (39.3)

5 (17.8)

3 (10.7)

$2(7.1)$

1.0

25 (89.3)

26 (92.9)

26 (92.9)

27 (96.4)

1.0

13 (44.4)

14 (46.2)

0.75

10 (37)

5 (18.6)

$4.6 \pm 2.2$

$26.8 \pm 6.1$

$0.8 \pm 0.3$

$89.0 \pm 19.6$

$3.2 \pm 2.7$

$11.7 \pm 2.4$

$60.8 \pm 6.5$

23 to 321

55.5 to 13,730

22 to 3,261

0 to 0.15
33 to 661

249

0.32

$11(42.3)$

3 (11.5)

$5.8 \pm 4.1$

$25.7 \pm 4.9$

$0.8 \pm 0.4$

0.72

$85.1 \pm 25.6$

0.53

$2.8 \pm 2.1$

0.59

$11.1 \pm 1.8$

0.33

$62.7 \pm 6.1$

15.2 to 7,709

1 (3.6)

120

0.85

17 to 3,078

0.003

0.83

0 to 0.12

0.11
58

268

1 (3.6)

117

0.003 
Table 1 Patient characteristics (Continued)

\begin{tabular}{lcc}
\hline Range & 25 to 516 & 24 to 204 \\
$\mathrm{dFLC}(\mathrm{mg} / \mathrm{L})$ & & 64.8 \\
Median & 96.1 & 14 to 163 \\
Range & 14 to 471 & 0 \\
$>180 \mathrm{mg} / \mathrm{L}(\%)$ & $2(7.1)$ & 0,12 \\
\hline a The upper reference limit for alkaline phosphatase is $172 \mathrm{U} / \mathrm{L}$. BNP, brain natriuretic peptide; ECOG PS, Eastern Cooperative Oncology Group performance status; \\
FLC, free light chain; GFR, glomerular filtration rate.
\end{tabular}

than one organ. The proportion of heart involvement in the BD + HDM/SCT and HDM/SCT group was $60.7 \%$ and $53.5 \%$, respectively; using biomarker cardiac staging criteria [32], the proportion of stage I, II, and III patients in the two groups were $50 \%$ versus $42.9 \%, 35.7 \%$ versus $39.3 \%$, and $14.3 \%$ versus $17.8 \%$, respectively. The laboratory findings for both groups demonstrated that nephrotic syndrome was the main clinical feature presented by all patients, and that there were no differences between the two groups at the time of diagnosis. BD induction therapy has been reported to quickly reduce the levels of involved FLCs (iFLCs) and dFLCs. Accordingly, the median values of iFLCs and dFLCs in the BD + HDM/SCT group had decreased by more than $50 \%$ prior to HDM/SCT.

\section{Treatment}

Of the 28 patients who underwent BD induction, 24 completed the treatment in accordance with the standard dose; four patients developed neuropathy and one patient experienced thrombocytopenia resulting in a dose reduction of bortezomib in the second cycle. Five patients developed grade 3 edema, resulting in a dose reduction of dexamethasone to $20 \mathrm{mg}$. A total of 14 patients in the $\mathrm{BD}+\mathrm{HDM} / \mathrm{SCT}$ group and 13 patients in the HDM/SCT group received $200 \mathrm{mg} / \mathrm{m}^{2}$ MEL whereas the other patients received $140 \mathrm{mg} / \mathrm{m}^{2} \mathrm{MEL}$ (Figure 1). The median number of stem cells collected was $5.5 \times 10^{6} \mathrm{CD}^{+} 4^{+} / \mathrm{kg}$ (range: 2 to $13.7 \times 10^{6} \mathrm{CD}^{+} 4^{+} / \mathrm{kg}$ ) in the BD $+\mathrm{HDM} / \mathrm{SCT}$ group and $3.5 \times 10^{6} \mathrm{CD} 4^{+} / \mathrm{kg}$ (range: 2.0 to $14.2 \times 10^{6} \mathrm{CD}^{+} 4^{+} / \mathrm{kg}$ ) in the HDM/SCT group $(P=0.13)$. The median granulocyte and platelet engraftment was 10 days and 13 days, respectively.

\section{Hematologic and organ responses}

The hematologic responses and organ response rate are summarized in Table 2 . The hematologic overall response rate (ORR) between the $\mathrm{BD}+\mathrm{HDM} / \mathrm{SCT}$ arm and HDM/ SCT arm at three, six and twelve months was $78.5 \%$ versus $50 \%, 82.1 \%$ versus $53.5 \%$ and $85.7 \%$ versus $53.5 \%$, respectively, and the $\mathrm{CR}$ at three, six and twelve months was $53.6 \%$ versus $21.4 \%, 60.7 \%$ versus $28.5 \%$ and $67.9 \%$ versus $35.7 \%$, respectively. The intention-to-treat (ITT) response rates calculated at 24 months in 20 and 23 patients for the BD + HDM/SCT and HDM/SCT arm were $80 \%$ and
$47.8 \%$, respectively. There were significant differences in hematologic $\mathrm{CR}$ among the patients who were evaluated a year after completing transplantation in the BD + HDM/ SCT group and the HDM/SCT group, at $67.9 \%$ in the former and $35.7 \%$ in the latter $(P=0.02)$. The 12 -month ORRs were also higher in the $\mathrm{BD}+\mathrm{HDM} / \mathrm{SCT}$ group (85.7\% versus $53.6 \%, P=0.04$ ), and this group also had higher CR rates at 3, 6 and 24 months. No significant difference was observed between the two groups with respect to the VGPR and PR and the disease progression (PD) rates. A total of 15 patients achieved hematologic response after induction therapy in the BD + HDM/SCT group, of whom eleven patients (39.2\%) achieved CR, two achieved VGPR, and two achieved PR. ORR after $\mathrm{BD}$ and prior to HDM/SCT in the BD + HDM/SCT arm was 53.5\%; seven of the other thirteen BD + HDM/SCT patients who exhibited NR to induction therapy achieved hematologic response at three months post-transplantation (two patients achieved CR, two patients achieved VGPR, and three patients achieved PR).

The ITT analysis of organ response (OR) between the two groups is also summarized in Table 2. A total of $65.2 \%(n=15)$ of the patients in the BD+HDM/SCT group and $39.1 \%(n=9)$ of patients in the HDM/SCT group experienced improvements in at least one involved organ by twelve months. When assessed by individual organ, the response rates of the kidneys and hearts in the $\mathrm{BD}+\mathrm{HDM} /$ SCT patients were higher than those of the HDM/SCT patients. However, the response rates of the liver and nervous system were similar between the two groups. In both groups, the OR rates of the surviving patients gradually increased with follow-up time.

\section{Survival and progression}

The median follow-up of the surviving patients was 28 months (range 12 to 8 months), and the data collection for the median PFS and OS is ongoing. The Kaplan-Meier curves for the PFS and OS are shown in Figure 2. Eight patients (two patients from the BD + HDM/SCT group and six patients from the HDM/SCT group) died during the follow-up period. One of these patients died from gastrointestinal bleeding, one died from sepsis, and the others died because of complications related to the progression of the disease. All patients who achieved 
Table 2 Hematological and organ responses

\begin{tabular}{|c|c|c|c|c|c|c|}
\hline \multirow[t]{4}{*}{ ITT } & \multicolumn{6}{|c|}{ Months post HDM/SCT } \\
\hline & 3 & 3 & 12 & 12 & 24 & 24 \\
\hline & $\mathrm{BD}+\mathrm{HDM} / \mathrm{SCT}$ & $\mathrm{HDM} / \mathrm{SCT}$ & $\mathrm{BD}+\mathrm{HDM} / \mathrm{SCT}$ & $\mathrm{HDM} / \mathrm{SCT}$ & $\mathrm{BD}+\mathrm{HDM} / \mathrm{SCT}$ & $\mathrm{HDM} / \mathrm{SCT}$ \\
\hline & Number = 28 & Number $=\mathbf{2 8}$ & Number = 28 & Number $=\mathbf{2 8}$ & Number $=20$ & Number $=23$ \\
\hline$\overline{C R}$ & $15(53.6 \%)^{a}$ & $6(21.4 \%)$ & $19(67.9 \%)^{a}$ & $10(35.7 \%)$ & $14(70 \%)^{a}$ & $8(34.8 \%)$ \\
\hline VGPR & $4(14.3 \%)$ & $4(14.3 \%)$ & $2(7.1 \%)$ & $3(10.7 \%)$ & $1(5 \%)$ & $1(4.3 \%)$ \\
\hline PR & $3(10.7 \%)$ & $4(14.3 \%)$ & $3(10.7 \%)$ & $2(2.1 \%)$ & $1(5 \%)$ & $2(8.7 \%)$ \\
\hline NR & $6(21.4 \%)$ & $12(42.8 \%)$ & $2(7.1 \%)$ & $6(21.4 \%)$ & $2(10 \%)$ & $3(13.0 \%)$ \\
\hline PD & - & - & $2(7.1 \%)$ & $3(10.7 \%)$ & $1(5 \%)$ & $3(13.0 \%)$ \\
\hline \multicolumn{7}{|c|}{ Organ responses } \\
\hline Kidney $^{\mathrm{b}}$ & & & $65.2 \%(15 / 23)$ & $39.1 \%(9 / 23)$ & $75 \%(12 / 16)$ & $53.8 \%(7 / 13)$ \\
\hline Heart $^{b}$ & & & $67 \%(10 / 15)$ & $25 \%(4 / 12)$ & $70 \%(7 / 10)$ & $50 \%(3 / 6)$ \\
\hline Liver $^{\mathrm{b}}$ & & & $100 \%(1 / 1)$ & $50 \%(1 / 2)$ & $100 \%(1 / 1)$ & $100 \%(1 / 1)$ \\
\hline$N S^{b}$ & & & $100 \%(3 / 3)$ & $100 \%(2 / 2)$ & $100 \%(3 / 3)$ & $100 \%(2 / 2)$ \\
\hline
\end{tabular}

${ }^{a}$ Compared with the HDM/SCT group, $P<0.05$; ${ }^{b}$ evaluable patients. CR, complete hematological response; ITT, intention-to-treat; NR, no response; NS, nervous system; PD, disease progression; PR, partial response; SD, stable disease; VGPR, very good partial response.

hematologic CR survived. Three patients in the BD + HDM/ SCT group and six patients in the HDM/SCT group had hematologic progression during the follow-up period. Two BD + HDM/SCT patients and three HDM/SCT patients received second-line treatment based on bortezomib or thalidomide, but only one of these patients had a hematologic (partial) response.

PFS and OS differed significantly between the two groups (Figure 2A and B). The patients in the BD + HDM/SCT group had better PFS and OS rates than the patients in the
HDM/SCT group. The estimated OS of the patients at 24 months was $95.0 \%$ in the $\mathrm{BD}+\mathrm{HDM} / \mathrm{SCT}$ group and $69.4 \%$ in the HDM/SCT group $(P=0.03)$; the estimated PFS of patients at 24 months was $80.7 \%$ in the BD + HDM/ SCT group and $51.1 \%$ in the HDM/SCT group $(P=0.01)$. The renal survival (Figure $2 \mathrm{C}$ ) at 24 months was $91.4 \%$ in the $\mathrm{BD}+\mathrm{HDM} / \mathrm{SCT}$ group and $62.6 \%$ in the HDM/SCT group $(P=0.02)$. Based on the Mayo cardiac staging system, those patients with stage III cardiac involvement had the worst OS rate (Figure 2D), and the median survival
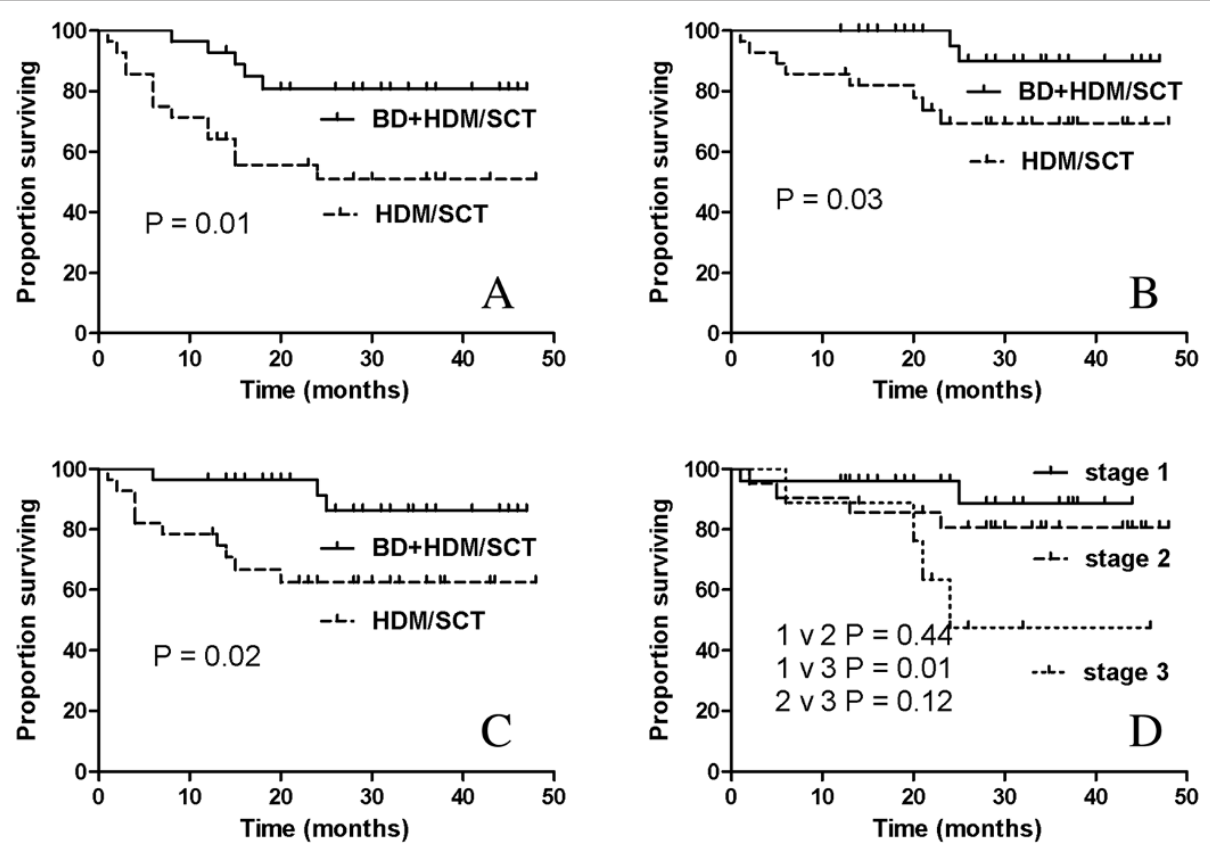

Figure 2 Progression free survival and overall survival. (A) The PFS of the two groups; (B) the OS of the two groups; (C) the renal survival rates of the two groups; and (D) The OS of all patients based on the Mayo cardiac staging system. 
was 24 months. In a multivariate analysis, only troponin-I (HR, 6.138; 95\% confidence interval (CI), 1.559 to 24.170; $P=0.009)$ was independently associated with survival (Table 3).

\section{Treatment-related mortality and toxicity}

In total, two patients died within 100 days posttransplantation, resulting in a TRM of $3.6 \%$. Both patients were in the HDM/SCT group: one death was cardiac related, occurring at +60 days, and the other death was caused by hepatic rupture, which occurred at +21 days. The treatment-related toxicities were similar between the two groups (Table 4), with gastrointestinal toxicity as the most common AE. The grade 3 and 4 AEs that were possibly related to $\mathrm{BD}$ induction are shown in Table 5. The hematological adverse events (grade 3 and 4) included 34\% thrombocytopenia, 15\% anemia and 7\% neutropenia. The most common non-hematologic BD toxicity was infection $(n=8)$, while herpes zoster infection was the most common type $(n=5)$. Edema was also a common toxicity during BD treatment: $17.9 \%(n=5)$ patients developed grade 3 edema.

\section{Discussion}

The HDM/SCT procedure for AL amyloidosis was introduced in 1998 by Comenzo et al., and represented a major breakthrough for AL amyloidosis [33]. Indeed accumulating data have indicated that HDM/SCT can suppress underlying monoclonal plasma cell disease and improve the patient's quality of life [34]. The purpose of induction chemotherapy is to reduce the light chain load and to improve organ function prior to HDM/SCT. Amyloidosis is characterized by a relatively small tumor mass, so small that induction chemotherapy is often not necessary before proceeding directly to highdose therapy. To date, the use of induction chemotherapy prior to HDM/SCT has been evaluated in a few studies, which have reported negative results. Pretreatment with two cycles of oral melphalan/prednisone prior to the transplantation did not improve the results of a prospective randomized trial [35]. Similarly, the data from Perz et al. [36] indicated that administering vincristine,
Table 4 Adverse events possibly related to HDM/SCT (Grade >2)

\begin{tabular}{lccc}
\hline Toxicity & $\begin{array}{c}\text { BD + HDM/SCT } \\
(\mathbf{n}=\mathbf{2 8})\end{array}$ & $\begin{array}{c}\text { HDM/SCT } \\
(\mathbf{n}=\mathbf{2 8})\end{array}$ & $\boldsymbol{P}$ value \\
\hline Nausea or vomiting & $8(28.6 \%)$ & $10(35.7 \%)$ & 0.78 \\
Diarrhea & $6(21.4 \%)$ & $7(25 \%)$ & 1.0 \\
Mucositis & $5(17.9 \%)$ & $7(25 \%)$ & 0.75 \\
Hepatic & $5(17.9 \%)$ & $5(17.9 \%)$ & 1.0 \\
Renal & $4(14.3 \%)$ & $6(21.4 \%)$ & 0.73 \\
Cardiac & $3(10.7 \%)$ & $6(21.4 \%)$ & 0.47 \\
Febrile neutropenia & $9(32.1 \%)$ & $7(25 \%)$ & 0.77 \\
Sepsis & 0 & $2(7.1 \%)$ & 0.5 \\
\hline
\end{tabular}

$\mathrm{BD}$, bortezomib in combination with dexamethasone; HDM/SCT, high dose melphalan and autologous stem cell transplantation.

doxorubicin and dexamethasone (VAD) before HDM/ SCT did not increase the hematologic response rate. Nonetheless, the outcome of $\mathrm{BD}$ induction prior to HDM/SCT has remained unknown.

Several studies have reported the results of adjuvant BD combination with HDM/SCT, and the addition of bortezomib to the HDM used as a conditioning regimen prior to stem-cell transplantation is feasible and well-tolerated by patients with AL amyloidosis [37]. The BD regimen has also been used following HDM/SCT to improve the depth of the response for patients who achieve less than VGPR. Nineteen of 28 patients received post-transplant BD chemotherapy, with $67 \%$ of these achieving CR and $60 \%$ organ responses [38]. A complementary approach of administering two cycles of BD prior to and as conditioning for HDM/SCT also yielded very good response rates of hematological remission in 9/18 patients after the induction, and all 11 patients evaluable after HDM/SCT attained CR/VGPR [39]. The combination of BD with cyclophosphamide has also shown encouraging response rates in patients with $\mathrm{AL}$ amyloidosis, even without high-dose therapy $[40,41]$. Additionally, most of the patients in these two series were either transplant ineligible or relapsed. Therefore, based on the current knowledge regarding the use of $\mathrm{BD}$ in the treatment of $\mathrm{AL}$ amyloidosis, it is clear that the $\mathrm{BD}$ regimen is effective and

Table 3 Factors associated with survival of all patients

\begin{tabular}{lccccc}
\hline Factors & \multicolumn{3}{c}{ Univariate } & & \multicolumn{2}{c}{ Multivariate } \\
\cline { 2 - 4 } & HR & $\mathbf{9 5 \% ~ C l}$ & $\boldsymbol{P}$ & HR & $\mathbf{9 5 \% ~ C l}$ \\
\hline Without BD induction & 4.730 & $1.003-22.307$ & 0.050 & 4.359 & $0.913-20.823$ \\
Urine protein $>3.5 \mathrm{~g} / 24$ hour & 1.2 & $0.310-4.647$ & 0.792 & & 0.065 \\
Cardiac stage III & 4.118 & $1.138-14.899$ & 0.031 & 1.272 & $0.276-5.864$ \\
Baseline BNP $>170 \mathrm{ng} / \mathrm{L}$ & 2.837 & $0.814-9.892$ & 0.104 & & 0.758 \\
Troponin-I >0.03 & 6.494 & $1.673-25.213$ & 0.007 & 6.138 & $1.559-24.170$ \\
The use of MEL 140 & 3.445 & $0.730-16.255$ & 0.118 & & 0.009 \\
\hline
\end{tabular}

$\mathrm{BD}$, bortezomib in combination wity dexamethasone; BNP, brain natriuretic peptide; $\mathrm{Cl}$, confidence interval; HR, hazard ratio; $\mathrm{MEL}$, melphalan. 
Table 5 Adverse events possibly related to BD induction

\begin{tabular}{lccc}
\hline Toxicity & Grade 3 & Grade 4 & Grade 5 \\
\hline Thrombocytopenia, number (\%) & $8(28.6 \%)$ & $1(3.6 \%)$ & 0 \\
Neutropenia, number (\%) & $2(7.1 \%)$ & 0 & 0 \\
Anemia, number (\%) & $4(14.3 \%)$ & 0 & 0 \\
Gastrointestinal, number (\%) & $7(25 \%)$ & 0 & 0 \\
Cardiac, number (\%) & $3(10.7 \%)$ & 0 & 0 \\
Infection, number (\%) & $8(28.6 \%)$ & 0 & 0 \\
Acute kidney injury, number (\%) & $2(7.1 \%)$ & 0 & 0 \\
Hepatic, number (\%) & $3(10.7 \%)$ & 0 & 0 \\
Neuropathy & $5(17.9 \%)$ & 0 & 0 \\
\hline
\end{tabular}

fast acting in patients with AL amyloidosis. Our data also show that BD therapy prior to HDM/SCT can quickly reduce the FLC level and the tumor burden and can furthermore delay the progress of involved organs, thus improving the safety and efficiency of HDM/SCT. Therefore, the $\mathrm{BD}$ regimen is an appropriate therapy before HDM/ $\mathrm{SCT}$. For patients who have already achieved CR prior to $\mathrm{HDM} / \mathrm{SCT}$, it is difficult to assess whether HDM/SCT was necessary, and only a clinical trial can provide an answer. Regardless, we believe that additional therapy with HDM/ SCT may be able to improve the depth of the response and further extend PFS of those patients.

Our data demonstrate that $\mathrm{BD}$ induction followed by risk-adapted HDM/SCT is a more effective strategy than $\mathrm{HDM} / \mathrm{SCT}$ alone for treating newly diagnosed patients with AL amyloidosis. The majority of patients (85.7\%) in the $\mathrm{BD}$ induction group achieved hematological responses, including more than half (67.9\%) who achieved $\mathrm{CR}$ at one year post-therapy. The BD induction group also displayed better PFS and OS rates than the group that received HDM/SCT alone. HDM/SCT treatment in patients with cardiac involvement remains challenging, particularly for patients with stage III cardiac involvement. In our series, $44.4 \%$ (4/9) of the patients with stage III cardiac involvement died during follow-up, but the median survival time was more favorable than previously reported [32].

The disadvantages of induction chemotherapy in patients with $\mathrm{AL}$ amyloidosis include the potential risk of side effects, the risk of further worsening organ function and the consequent delay of HDM/SCT. Our data demonstrate that the majority of patients can tolerate two cycles of $\mathrm{BD}$ treatment, and that the toxicity of the $\mathrm{BD}$ regimen is moderate and manageable. All toxicities were reversible and did not influence the subsequent HDM/SCT procedure because MEL toxicity differs from that of bortezomib. However, additional attention should be given to some toxicities that can result in bortezomib or dexamethasone dose reduction, including edema, peripheral neuropathy, and thrombocytopenia. Edema is a common toxicity for high-dose dexamethasone, particularly in patients with renal involvement and low serum albumin levels. Because the serum albumin levels of all five patients who developed grade 3 edema were lower than $2 \mathrm{~g} / \mathrm{dl}$, support treatment with diuretics and serum albumin is important for these patients. Peripheral neuropathy also needs to be carefully monitored during BD induction, as $18 \%$ of the patients developed grade 3 neuropathy in this study, apparently higher than in other studies [24,25]. One study demonstrated that $1.6 \mathrm{mg} / \mathrm{m}^{2}$ once-weekly bortezomib dosing can reduce toxicity compared to $1.3 \mathrm{mg} / \mathrm{m}^{2}$ twiceweekly dosing [42]. Subcutaneous bortezomib is another option to reduce the incidence of peripheral neuropathy and has been confirmed in a randomized, phase 3 study for multiple myeloma patients [43] and was also proven in a small series of AL amyloidosis patients [44]. In addition, we observed a high incidence of herpes zoster infection during BD induction; thus, anti-virus prophylaxis appears to be necessary for these patients. In our study, the occurrence of TRM in our study population of 56 patients was $3.6 \%(2 / 56)$, a lower value than in most reports. Moreover, no patients in the BD induction group died because of treatment-related complications. The possible reasons for the relatively low TRM observed include the risk-adapted approach of HDM/SCT, the induction chemotherapy used in half of the patients, the small proportion of patients with severe cardiac involvement and racial differences.

This study has several limitations. First, all of the patients had renal involvement, which most likely constitutes a selection bias because the study was conducted in a nephrology institution. Second, neither group met the median PFS and OS rates, and the long-term patient prognosis requires further study. Third, it is unclear whether the PFS rate of the patients who achieved CR after the BD induction following HDM/SCT is equivalent to the $\mathrm{CR}$ achieved with BD therapy alone. Fourth, the sample size of this trial is too small to allow patient stratification based on known risk factors, as well as to allow a subgroup analysis, so the results for stratification or subgroup analysis cannot match the results of other studies. We will continue this study and enroll more patients to make this stratification or subgroup analysis more clear. Additionally, the appropriate salvage regimen for patients who had no response to $\mathrm{BD}$ induction following HDM/SCT is also unclear.

\section{Conclusions}

In conclusion, our preliminary data suggest that induction therapy with $\mathrm{BD}$ followed by HDM/SCT is an effective and tolerable regimen for treating patients with AL amyloidosis. This protocol can significantly improve both the hematological and organ response rates, and the risk of the $\mathrm{BD}+\mathrm{HDM} / \mathrm{SCT}$ regimen is apparently comparable to that of HDM/SCT. Although HDM/SCT remains a high-risk treatment modality for AL amyloidosis, new 
agents, such as bortezomib, may alter this therapeutic approach and improve patient outcomes. Further study will be required to establish the long-term benefits of this treatment.

\section{Abbreviations}

AEs: adverse events; BD: bortezomib in combination with dexamethasone; BNP: brain natriuretic protein; CR: complete response; ECOG: Eastern Cooperative Oncology Group; FLC: free light chains; HDM/SCT: high dose melphalan and autologous stem cell transplantation; HRs: hazard ratios; ITT: intention to treat; MEL: melphalan; NR: no response; OR: organ response; ORR: overall response rate; OS: overall survival; PD: disease progression; PFS: progression free survival; PR: partial response; TRM: treatment-related mortality; VAD: vincristine doxorubicin and dexamethasone; VGPR: very good partial response.

\section{Competing interests}

The authors declare that they have no competing interests.

\section{Authors' contributions}

$\mathrm{ZL}, \mathrm{XH}$ and $\mathrm{QW}$ designed and performed the research, analyzed the data and wrote the paper. WC performed research and analyzed data. $\mathrm{XH}, \mathrm{QW}$, WC, $C Z, Z C, D G, H Z$ and $Z L$ took care of the patients. All of the authors read and approved the final manuscript.

\section{Acknowledgments}

Part of this work was presented as a poster at the 2013 World Congress of Nephrology in Hong Kong, China, 31 May to 4 June 2013. This work was supported by the National Key Technology R\&D Program (No. 2013BAl09B04) and the Clinical Research Program of Jiangsu Province (No. BL2012007).

Received: 20 September 2013 Accepted: 6 December 2013 Published: 6 January 2014

\section{References}

1. Merlini G, Bellotti V: Molecular mechanisms of amyloidosis. N Engl I Med 2003, 349:583-596.

2. Comenzo RL: Amyloidosis. Curr Treat Options Oncol 2006, 7:225-236.

3. Kyle RA, Gertz MA, Greipp PR, Witzig TE, Lust JA, Lacy MQ, Therneau TM: Long-term survival (10 years or more) in 30 patients with primary amyloidosis. Blood 1999, 93:1062-1066.

4. Palladini G, Merlini G: Current treatment of AL amyloidosis. Haematologica 2009, 94:1044-1048.

5. Rajkumar SV, Gertz MA: Advances in the treatment of amyloidosis. N Engl J Med 2007, 356:2413-2415.

6. Gertz MA, Lacy MQ, Lust JA, Greipp PR, Witzig TE, Kyle RA: Prospective randomized trial of melphalan and prednisone versus vincristine, carmustine, melphalan, cyclophosphamide, and prednisone in the treatment of primary systemic amyloidosis. J Clin Oncol 1999, 17:262-267.

7. Skinner M, Anderson J, Simms R, Falk R, Wang M, Libbey C, Jones LA, Cohen AS: Treatment of 100 patients with primary amyloidosis: a randomized trial of melphalan, prednisone, and colchicine versus colchicine only. Am J Med 1996, 100:290-298.

8. Palladini G, Perfetti V, Obici L, Caccialanza R, Semino A, Adami F, Cavallero G, Rustichelli R, Virga G, Merlini G: Association of melphalan and high-dose dexamethasone is effective and well tolerated in patients with $\mathrm{AL}$ (primary) amyloidosis who are ineligible for stem cell transplantation. Blood 2004, 103:2936-2938.

9. Palladini G, Russo P, Nuvolone M, Lavatelli F, Perfetti V, Obici L, Merlini G: Treatment with oral melphalan plus dexamethasone produces long-term remissions in AL amyloidosis. Blood 2007, 110:787-788.

10. Gertz MA: Immunoglobulin light chain amyloidosis: 2013 update on diagnosis, prognosis, and treatment. Am J Hematol 2013, 88:416-425.

11. Skinner M, Sanchorawala V, Seldin DC, Dember LM, Falk RH, Berk JL, Anderson JJ, O'Hara C, Finn KT, Libbey CA, Wiesman J, Quillen K, Swan N, Wright DG: High-dose melphalan and autologous stem-cell transplantation in patients with AL amyloidosis: an 8-year study. Ann Intern Med 2004, 140:85-93.

12. Gertz MA, Lacy MQ, Dispenzieri A, Hayman SR, Kumar SK, Leung N, Gastineau DA: Effect of hematologic response on outcome of patients undergoing transplantation for primary amyloidosis: importance of achieving a complete response. Haematologica 2007, 92:1415-1418.
13. Gertz MA, Lacy MQ, Dispenzieri A: Myeloablative chemotherapy with stem cell rescue for the treatment of primary systemic amyloidosis: a status report. Bone Marrow Transplant 2000, 25:465-470.

14. Sanchorawala V, Wright DG, Seldin DC, Dember LM, Finn K, Falk RH, Berk J, Quillen K, Skinner M: An overview of the use of high-dose melphalan with autologous stem cell transplantation for the treatment of AL amyloidosis. Bone Marrow Transplant 2001, 28:637-642.

15. Moreau P, Leblond V, Bourquelot P, Facon T, Huynh A, Caillot D, Hermine $O$, Attal M, Hamidou M, Nedellec G, Ferrant A, Audhuy B, Bataille R, Milpied N, Harousseau JL: Prognostic factors for survival and response after high-dose therapy and autologous stem cell transplantation in systemic AL amyloidosis: a report on 21 patients. Br J Haematol 1998, 101:766-769.

16. Palladini $\mathrm{G}$, Merlini $\mathrm{G}$ : Transplantation vs. conventional-dose therapy for amyloidosis. Curr Opin Oncol 2011, 23:214-220.

17. Palladini G, Perfetti V, Perlini S, Obici L, Lavatelli F, Caccialanza R, Invernizzi R, Comotti B, Merlini $\mathrm{G}$ : The combination of thalidomide and intermediate-dose dexamethasone is an effective but toxic treatment for patients with primary amyloidosis (AL). Blood 2005, 105:2949-2951.

18. Wechalekar AD, Goodman HJ, Lachmann HJ, Offer M, Hawkins PN, Gillmore JD: Safety and efficacy of risk-adapted cyclophosphamide, thalidomide, and dexamethasone in systemic AL amyloidosis. Blood 2007, 109:457-464.

19. Sanchorawala V, Wright DG, Rosenzweig M, Finn KT, Fennessey S, Zeldis JB, Skinner M, Seldin DC: Lenalidomide and dexamethasone in the treatment of AL amyloidosis: results of a phase 2 trial. Blood 2007, 109:492-496.

20. Kastritis E, Anagnostopoulos A, Roussou M, Toumanidis S, Pamboukas C, Migkou M, Tassidou A, Xilouri I, Delibasi S, Psimenou E, Mellou S, Terpos E, Nanas J, Dimopoulos MA: Treatment of light chain (AL) amyloidosis with the combination of bortezomib and dexamethasone. Haematologica 2007, 92:1351-1358.

21. Richardson PG, Sonneveld P, Schuster MW, Irwin D, Stadtmauer EA, Facon T, Harousseau JL, Ben-Yehuda D, Lonial S, Goldschmidt H, Reece D, San-Miguel JF, Blade J, Boccadoro M, Cavenagh J, Dalton WS, Boral AL, Esseltine DL, Porter $J B$, Schenkein D, Anderson KC: Bortezomib or high-dose dexamethasone for relapsed multiple myeloma. N Engl J Med 2005, 352:2487-2498.

22. San MJ, Schlag R, Khuageva NK, Dimopoulos MA, Shpilberg O, Kropff M, Spicka I, Petrucci MT, Palumbo A, Samoilova OS, Dmoszynska A, Abdulkadyrov KM, Schots R, Jiang B, Mateos MV, Anderson KC, Esseltine DL, Liu K, Cakana A, van de Velde H, Richardson PG: Bortezomib plus melphalan and prednisone for initial treatment of multiple myeloma. N Eng/ J Med 2008, 359:906-917.

23. Wechalekar AD, Lachmann HJ, Offer M, Hawkins PN, Gillmore JD: Efficacy of bortezomib in systemic AL amyloidosis with relapsed/refractory clonal disease. Haematologica 2008, 93:295-298.

24. Reece DE, Sanchorawala V, Hegenbart U, Merlini G, Palladini G, Fermand JP, Vescio RA, Liu X, Elsayed YA, Cakana A, Comenzo RL: Weekly and twice-weekly bortezomib in patients with systemic AL amyloidosis: results of a phase 1 dose-escalation study. Blood 2009, 114:1489-1497.

25. Kastritis E, Wechalekar AD, Dimopoulos MA, Merlini G, Hawkins PN, Perfetti V, Gillmore JD, Palladini G: Bortezomib with or without dexamethasone in primary systemic (light chain) amyloidosis. J Clin Oncol 2010, 28:1031-1037.

26. Gertz MA, Comenzo R, Falk RH, Fermand JP, Hazenberg BP, Hawkins PN, Merlini G, Moreau P, Ronco P, Sanchorawala V, Sezer O, Solomon A, Grateau $\mathrm{G}$ : Definition of organ involvement and treatment response in immunoglobulin light chain amyloidosis (AL): a consensus opinion from the 10th International Symposium on Amyloid and Amyloidosis, Tours, France, 18-22 April 2004. Am J Hematol 2005, 79:319-328.

27. Kyle RA, Rajkumar SV: Criteria for diagnosis, staging, risk stratification and response assessment of multiple myeloma. Leukemia 2009, 23:3-9.

28. Oken MM, Creech RH, Tormey DC, Horton J, Davis TE, McFadden ET, Carbone PP: Toxicity and response criteria of the Eastern Cooperative Oncology Group. Am J Clin Oncol 1982, 5:649-655.

29. Comenzo RL, Gertz MA: Autologous stem cell transplantation for primary systemic amyloidosis. Blood 2002, 99:4276-4282.

30. Palladini G, Dispenzieri A, Gertz MA, Kumar S, Wechalekar A, Hawkins PN, Schonland S, Hegenbart U, Comenzo R, Kastritis E, Dimopoulos MA, Jaccard A, Klersy C, Merlini G: New criteria for response to treatment in immunoglobulin light chain amyloidosis based on free light chain measurement and cardiac biomarkers: impact on survival outcomes. J Clin Oncol 2012, 30:4541-4549.

31. Comenzo RL, Reece D, Palladini G, Seldin D, Sanchorawala V, Landau H, Falk R, Wells K, Solomon A, Wechalekar A, Zonder J, Dispenzieri A, Gertz M, Streicher H, Skinner M, Kyle RA, Merlini G: Consensus guidelines for the 
conduct and reporting of clinical trials in systemic light-chain amyloidosis. Leukemia 2012, 26:2317-2325.

32. Dispenzieri A, Gertz MA, Kyle RA, Lacy MQ, Burritt MF, Therneau TM, Greipp PR, Witzig TE, Lust JA, Rajkumar SV, Fonseca R, Zeldenrust SR, McGregor CG, Jaffe AS: Serum cardiac troponins and $\mathrm{N}$-terminal pro-brain natriuretic peptide: a staging system for primary systemic amyloidosis. J Clin Oncol 2004, 22:3751-3757.

33. Comenzo RL, Vosburgh E, Simms RW, Bergethon P, Sarnacki D, Finn K, Dubrey S, Faller DV, Wright DG, Falk RH, Skinner M: Dose-intensive melphalan with blood stem cell support for the treatment of AL amyloidosis: one-year follow-up in five patients. Blood 1996, 88:2801-2806.

34. Seldin DC, Anderson JJ, Sanchorawala V, Malek K, Wright DG, Quillen K, Finn KT, Berk JL, Dember LM, Falk RH, Skinner M: Improvement in quality of life of patients with AL amyloidosis treated with high-dose melphalan and autologous stem cell transplantation. Blood 2004, 104:1888-1893.

35. Sanchorawala V, Wright DG, Seldin DC, Falk RH, Finn KT, Dember LM, Berk JL, Quillen K, Anderson JJ, Comenzo RL, Skinner M: High-dose intravenous melphalan and autologous stem cell transplantation as initial therapy or following two cycles of oral chemotherapy for the treatment of AL amyloidosis: results of a prospective randomized trial. Bone Marrow Transplant 2004, 33:381-388.

36. Perz JB, Schonland SO, Hundemer M, Kristen AV, Dengler TJ, Zeier M, Linke RP, Ho AD, Goldschmidt H: High-dose melphalan with autologous stem cell transplantation after VAD induction chemotherapy for treatment of amyloid light chain amyloidosis: a single centre prospective phase II study. Br J Haematol 2004, 127:543-551.

37. Sanchorawala V, Quillen K, Sloan JM, Andrea NT, Seldin DC: Bortezomib and high-dose melphalan conditioning for stem cell transplantation for AL amyloidosis: a pilot study. Haematologica 2011, 96:1890-1892.

38. Landau H, Hassoun H, Rosenzweig MA, Maurer M, Liu J, Flombaum C, Bello C, Hoover E, Riedel E, Giralt S, Comenzo RL: Bortezomib and dexamethasone consolidation following risk-adapted melphalan and stem cell transplantation for patients with newly diagnosed light-chain amyloidosis. Leukemia 2013, 27:823-828.

39. Sanchorawala V, Alam M, Shelton A, Brauneis D, Andrea NT, Sloan JM, Seldin DC: Treatment of AL amyloidosis with 2 cycles of induction therapy with bortezomib and dexamethasone followed by bortezomib-high dose melphalan conditioning and autologous stem cell transplantation. XIllth International Symposium on Amyloidosis, 2012. PC53.

40. Mikhael JR, Schuster SR, Jimenez-Zepeda VH, Bello N, Spong J, Reeder CB, Stewart AK, Bergsagel PL, Fonseca R: Cyclophosphamide-bortezomib-dexamethasone (CyBorD) produces rapid and complete hematologic response in patients with AL amyloidosis. Blood 2012, 119:4391-4394.

41. Venner CP, Lane T, Foard D, Rannigan L, Gibbs SD, Pinney JH, Whelan CJ, Lachmann HJ, Gillmore JD, Hawkins PN, Wechalekar AD:

Cyclophosphamide, bortezomib, and dexamethasone therapy in AL amyloidosis is associated with high clonal response rates and prolonged progression-free survival. Blood 2012, 119:4387-4390.

42. Reece DE, Hegenbart U, Sanchorawala V, Merlini G, Palladini G, Blade J, Fermand JP, Hassoun H, Heffner L, Vescio RA, Liu K, Enny C, Esseltine DL, van de Velde H, Cakana A, Comenzo RL: Efficacy and safety of once-weekly and twice-weekly bortezomib in patients with relapsed systemic $\mathrm{AL}$ amyloidosis: results of a phase 1/2 study. Blood 2011, 118:865-873.

43. Moreau P, Pylypenko H, Grosicki S, Karamanesht I, Leleu X, Grishunina M, Rekhtman G, Masliak Z, Robak T, Shubina A, Arnulf B, Kropff M, Cavet J, Esseltine DL, Feng H, Girgis S, van de Velde H, Deraedt W, Harousseau JL: Subcutaneous versus intravenous administration of bortezomib in patients with relapsed multiple myeloma: a randomised, phase 3, non-inferiority study. Lancet Oncol 2011, 12:431-440.

44. Shah G, Kaul E, Fallo S, Cossor F, Smith H, Spraque K, Klein A, Miller K, Comenzo R: Bortezomib subcutaneous injection in combination regimens for myeloma or systemic light-chain amyloidosis: a retrospective chart review of response rates and toxicity in newly diagnosed patients. Clin Ther 2013, 35:1614-1620.

doi:10.1186/1741-7015-12-2

Cite this article as: Huang et al:: Induction therapy with bortezomib and dexamethasone followed by autologous stem cell transplantation versus autologous stem cell transplantation alone in the treatment of renal AL amyloidosis: a randomized controlled trial. BMC Medicine 2014 12:2.

\section{Submit your next manuscript to BioMed Central and take full advantage of:}

- Convenient online submission

- Thorough peer review

- No space constraints or color figure charges

- Immediate publication on acceptance

- Inclusion in PubMed, CAS, Scopus and Google Scholar

- Research which is freely available for redistribution 